DOI 10.15826/B978-5-7996-3073-7.2

Janna M. Glozman

Lomonosov Moscow State University,

Moscow, Russia

\title{
Lurian neuropsychological assessment at an early age
}

Abstract. The paper discusses the theoretical foundations and methods of neuropsychological assessment of 2-6-year-old preschool children and describes the potential and advantages of Luria's battery for revealing child underdevelopment or abnormal development.

Keywords: neuropsychological assessment; preschool children; Luria's battery; scoring.

Introduction. A. R. Luria, L. S. Vygotsky and developmental neuropsychology

L. S. Vygotsky and A. R. Luria revealed "a bifurcation in the course of a child's behavioral development into natural-psychological and cultural-psychological development" [1, p. 30]. They have proved that a defect interferes with a child's appropriation of the culture, but cultural means can be used to help the child overcome the defect. Thus, the cultural-historical approach has become a methodological basis for remediating education and developmental neuropsychology in general.

Lurian qualitative approach, that is, the qualitative analysis of different types of errors made by a child during the neuropsychological assessment and their possible correction, identifies a whole range of defects, depending on the maturity of the tested function, the zone of its proximal development as well as the state of various components in the structure of the specific mental function and other functions with common components.

The main goals of the child neuropsychological assessment

Lurian neuropsychological analysis differentiates between learning and behavior problems caused by the lack of maturation and/or individual features of brain structures caused by the maladjustment associated with poor teaching methods or pathological features of the child's personality.

Not only can a disease provoke certain biological processes that would hinder the child's development, but it may also interfere with the psycholog- 
ical and social development such as personality formation, acquiring new knowledge and mastering new skills. On the other hand, a poor or belated psychological or educational action may also cause developmental delays in children or deviations in the development of their functional systems.

The up-to-date Lurian neuropsychological analysis is a poly-causal analysis aimed to determine how different biological and social causes of dysontogenesis interact and determine the type of abnormal development in each child

\section{Why is it important to assess preschoolers?}

Assessment of preschoolers helps reveal delayed mental functions and determine their possible impact on child learning; prevent the learning disability at school or kindergarten and its emotional consequences.

Neuropsychological assessment of preschoolers is very likely to identify the risk of possible future learning problems. Such children need a neuropsychological follow-up and dynamic evaluation of their functional state. In addition, the qualitative description of differentiated features, strengths and weaknesses in mental functioning of each particular child is essential for helping these children overcome their developmental and learning problems.

Age differences in the neuropsychological assessment of preschoolers

The testing material must meet the following criteria:

- It should be accessible for each age group,

- It should be familiar to each age group,

- It should attract attention and incite interest,

- It should use diverse methods and materials for each age group,

- The younger is the child, the higher is the rate of game analogies of neuropsychological tests, observations and parents interview.

- At any age, both the test or its game analogies must follow Luria's principle of polymodality - to give information about different mental functions [2].

How to prevent exhaustibility and deal with the problem of low concentration and attention stability at a preschool age?

- To give the child an option to switch to another activity after about 10-20 minutes of testing;

- To select the most informative and time-saving techniques to ensure the compactness of methods; 
- To use diverse tasks;

- To present each pair of stimuli separately to limit the volume of visual perception;

- To subdivide the instruction in two parts to limit the volume of acoustic perception;

- To organize a situation of competition to boost the child's motivation for testing;

- To use game-based tasks (games are particularly important at a preschool age) $[3,4]$.

Conclusions

- Pediatric neuropsychology is a young but rapidly developing science.

- Lurian approach to neuropsychological assessment of children means a shift from the phenomenological description of the observed defects in mental functioning to revealing their mechanisms and organizing the assessment in such a way to allow the child to compensate for his or her difficulties. This is done through dialogue interaction and consecutive transfer from implementation of the test together with the neuropsychologist to an independent one.

- A neuropsychological survey should not create "a negative picture of the child" [5] but to identify the strengths of his or her mental functioning and the potential for its development.

- It is necessary to understand and overcome the impediments to the child's life in harmony and agreement with his or her environment.

1. Vygotskij L. S., Luriya A.R. Etyudy po istorii povedeniya. M.: Gosizdat, 1930. [In Russian].

2. Luria A. R. The Working Brain. An Introduction to Neuropsychology. London: Penguin Books, 1973.

3. Glozman J.M. Developmental neuropsychology. London - New York: Psychology Press - Taylor and Francis group, 2013.

4. Glozman J. M. A prática neuropsicológica fundamentada em Luria e Vygotsky: Avaliação, abilitação e reabilitação. San Paulo: Memnon, 2014.

5. Vygotskij L. S. Izbrannye psihologicheskie issledovaniya. M.: Izdatel'ctvo Akademii pedagogicheskih nauk RSFSR, 1956. [In Russian]. 